\title{
Editorial
}

\section{PLANTS IN HEALTHCARE: PAST, PRESENT AND FUTURE}

\author{
Shibabrata Pattanayak*
}

\begin{abstract}
Plants have been used as medicines or sources of medicines from a very ancient stage of human civilization. In the ancient days, the collected plant parts were used directly or in dried and preserved conditions. Afterward, the dried parts of the medicinal plants were used as medicine as single or poly-herbal mixtures with or without vehicle as used in present-day Ayurveda and alike medical systems. In homeopathy, the ethanol extracts of dried plant parts are used. Identification of active principles from the extracts of the dried plant parts has made the basis of laboratory synthesis of many drugs of modern medicine. Some novel types of healthcare techniques are proposed for further validation. Following a diet containing selected herbal foods (DIP diet) in an unprocessed state along with a change in lifestyle can control many diseases. Fruit pulp, fruit juice and other related food products can be prepared by using only herbal plant parts and also can be supplied without the addition of any synthetic chemicals. Similarly, medicines prepared from the succulent parts of the medicinal plants can effectively be used to prevent and cure many diseases. All these can be performed following some novel procedures of collection, chemical-free processing, packaging, storage, and transportation to the patients and consumers.
\end{abstract}

Key words: Herbal medicine, Active principle, DIP diet, Succulent biomedicine.

\section{HISTORY OF USE OF PLANTS AS MEDICINE}

Plants have been used in healthcare from a very early stage of human civilization. The Neanderthals burial site (60000 years ago) (Solecki 1975), belongings of Ötzi the Iceman of 5000 years ago (Capasso 1998) etc. are some ancient examples where medicinal plant parts were found with the human. Among the written documents, the oldest one was found on a Sumerian clay slab of almost 5000 years old (Petrovska 2012). Other ancient pieces of evidence found were in the Chinese book "Pen TS'ao," written by Shen Nung of 2500 BC, in Egyptian Ebers Papyrus of 1550 BC (Petrovska 2012), Indian Ayurvedic medicine documented in the Vedas and Sushruta Samhita between 1500 - 500 BC (Aggarwal et al. 2007, Dwivedi and Dwivedi 2007), in Homer's epics - the Iliad and the Odysseys of $800 \mathrm{BC}$, in the works of Hippocrates of 459370 BC, Dioscorides (considered as the father of Pharmacology) in his book "De Materia Medica of 77 AD (Petrovska 2012) etc.

On our planet, there are about 374,000 estimated plant species, of which 308,312 are vascular plants which include 295,383 flowering plants (Christenhusz and Byng 2016). India is among the leading biodiversity centers of the world for holding over 45,000 different plant species (Asthana et al. 2012). Out of 15000-17000 medicinal plants, about 3000 - 7500 species are used traditionally for medicinal purposes (Meena et al. 2009, Pattanayak 2012). Among the Indian traditional systems, Ayurveda (700), Unani (700), Siddha (600), and Amchi (600) are the main users of medicinal plants for therapeutic purposes (Rabe and Staden 1997). In Homeopathy, over 800 species of plants are used (Bharatan 2008).

The use of plants directly for medicinal purposes is not only a practice of the past. Even today, several ethnic and rural people use medicinal plants for their healthcare throughout the globe. As per WHO estimate, almost 80 percent of the world population depends mainly on traditional medicines, a large part of which is of herbal origin (Farnsworth 1985). The main reasons behind such widespread use of plant resources in healthcare are local availability and limited access to modern medicines (Pattanayak et al. 2012).

\footnotetext{
Assistant Director, ARD (Vet. Res. Invest.), Govt. of West Bengal, India and Associate Editor, Exploratory Animal and Medical Research.

*Corresponding author. e-mail: pattanayak1966@gmail.com
} 


\section{RESEARCH ON THE USE OF PLANTS AS} MEDICINE

\section{A. Documentation of medicinal uses of plants i) Documentation in the ancient era}

During the ancient days, the use of the plants for different medicinal purposes was either not documented and the knowledge was passed for generations from the medicine men/women to their disciples or documented in some cases by local names (Sen and Sen 2005). With the passage of time, and with changes of the colloquial languages, such vernacular plant names have also changed. So, information about many important medicinal plants may have also been lost or not available now or the plant may also be extinct or non-identifiable at the present time (Sen and Sen 2005, Pattanayak 2012).

After the introduction of the scientific techniques of nomenclature for all the living species of our planet (plants, animals, etc.) by Carolus Linnaeus (1707 - 1778), the scientific nomenclature of the plants was started replacing local or colloquial names and the old or traditional uses of the plants are also documented afterward using these internationally accepted names (Pearson 2003).

Identification of actual plants from the ancient documented names and descriptions by analysis of different related points along with infield study of the said living plant species following scientific procedures and collection of information regarding their medicinal uses from the ancient texts and literature are very much important. Along with available documented ethnomedicinal reports, infield surveys to collect further information from the medicine men and medicine women as well as other rural people etc. made the platform of that study far more diverse and important.

\section{ii) Recent trends in documentation}

The early documentation works were performed either by plant Family-wise (as all the effective plants of a Family were listed with their reported uses) or individually without following any such system. In India, many early epic works of high significance have actually formed the basis for the works at a later stage (The wealth of India 1949, Chopra et al. 1956, Uphof 1968) and also a brief description of some selected important medicinal plants in the edited book by Ambasta (1986).

During the last few years, documentation of the use of medicinal plants as per their activity of a certain type has been observed. Plants used for the protection of some organ or organ-system are available to us from those pieces of literature (Pattanayak et al. 2016a, Pattanayak et al. 2016c, Nirumand et al. 2018). Reports on the use of medicinal plants in different geographical areas have also provided important information and enriched our knowledge base (Kutalek and Prinz 2005, Pattanayak et al. 2015a, Pattanayak et al. 2015b).

Another important type of cataloging of plants has been done based on possible medicinal activities of plants on the body systems by dietary use in their raw form to serve definite purposes. The use of the medicinal plants in a definite therapeutic purpose based on the systemic effects of all the nature-gifted phytochemicals inside them is the target of these studies. Such documentations are analytical in nature and can act as ready references for initiating research to validate their abilities as medicines. Use of plants against infectious diseases (Pattanayak 2019a, Khameneh et al. 2019, Pattanayak 2019b), as immunomodulators and body system-modifier to control different diseases (Pattanayak 2020, Pattanayak 2021), etc. are examples.

\section{A. Contemporary research on medicinal activities of plants}

i) Ayurveda and other similar systems of medicine

Ayurveda is considered the science of life with a holistic approach to health and personalized medicine. It is one of the oldest medicines containing thousands of medical concepts and hypotheses. Many people trust the ability of this system to treat different diseases such as cancer, asthma, diabetes, etc. which are not easily treatable in modern medicine (Chauhan et al. 2015).

Dry parts of the medicinal herbs singly or as polyherbal formulations are generally used in Ayurveda. The dry medicinal parts of the plants are generally converted to smaller parts and used with or without a vehicle, covered by capsules in a few cases (as soft gel capsules or hard capsules) in Ayurveda and many other similar traditional systems of medicines. In a few cases, some other type of uses of medicinal parts of plants is also practiced (such as decoction of herbal parts, use of essential oils, use of vapors etc.).

In the present day, research is mainly targeted to validate the activities documented in the various medical texts of Ayurveda and other similar systems in the eyes of modern science by using currently available research tools and techniques (Meena et al. 2009, Chauhan et al. 2015). So, research in Ayurveda is mainly targeted in the fields of collection of information from ancient literature, fundamental uses, understanding of the drugs as well as research on their pharmaceutical and clinical research activities (Chauhan et al. 2015). 


\section{ii) Homeopathy}

In Homeopathy, alcoholic (ethyl alcohol generally) extracts of dry parts of medicinal plants at different levels of dilutions are generally used as medicines. Research on the collection of information and clinical trials is given much importance in Homeopathic medicine. The broad research activities in Homeopathy are - survey, collection, and cultivation of medicinal plants, standardization of drugs, proving of activities of the drugs, clinical verification of drugs, and clinical research on Homeopathic drugs (CCRH 2018).

\section{iii) Modern medicine}

In modern medicine, research is mainly conducted towards the development of marketable synthetic or semisynthetic medicines using plants as some source (Pattanayak et al. 2016b).

For the development of a new drug, validation of traditional claims or other literature reports is performed as the first step. Different solvent (such as methyl alcohol, ethyl alcohol, acetone etc.) extracts of the dry parts of the medicinal plants are studied for their reported activities. If any fraction of the solvent extract shows the desired activity, studies are performed to identify the effective (active) principle(s) involved in such activity. Then further studies are conducted on laboratory synthesis of structural analogs of such active principles, determination of their dose and toxicity before marketing of the active drug as medicine (Pattanayak et al. 2016b, Pattanayak 2018, Khameneh et al. 2019).

\section{B. Emerging windows of development of therapeutics from herbal origin}

As a part of the modern lifestyle, people are becoming dependent more and more on processed foods and foods added with different synthetic chemicals. The cumulative effects of all such synthetic chemicals taken regularly may have serious impacts on our health (Pattanayak 2017). So, following an alternative to such dependence on the use of synthetic chemicals in food and medicine may reduce the bio-burden of chemicals and so the chance of development of several diseases.

Apart from the different contemporary systems of medicine involving the use of dry parts or their extracts of different nature to control and cure diseases, some new concepts are emerging in the area of use of plants as some biomedicines. Two main systems can be discussed under this category which are interrelated and may be considered as having relation with the Indian traditional healthcare system, Ayurveda. These two sections are advocated along with following the desired lifestyle involving ample daily physical exercise, restriction in some unhealthy activities, living without any narcotics or alcohol, following tension-free life etc. Among these two, one focuses on eating fruits, vegetables and nuts as a major part of the diet, eating of preservatives and all other added chemical-free fruit, fruit juice, ice cream, etc.; use of skincare, haircare, etc. preparations made solely from herbs without the addition of any synthetic chemicals, etc. The other one is the therapeutic use of parts of the medicinal plants at their succulent stages.

\section{i) Novel concepts of use of unaltered herbal parts} as food and healthcare

a) The DIP diets

"The disciplined and intelligent peoples' diet" (DIP diet) is mainly a plant-based diet plan with some protocols for breakfast, lunch, dinner etc. The fruits and nuts listed for use under this diet plan are to be taken in their raw, succulent form. It is claimed that people can stay away from diseases like high blood pressure, diabetes, thyroid problems, kidney diseases, arthritis, liver disease, cancers, obesity etc. by practicing this diet plan (Roy Chowdhury 2021).

A study was conducted on 55 diabetic persons kept on a selected raw fruit and vegetable diet for three days within some lifestyle restrictions. Among them, $84 \%$ of patients showed marked improvements, and $16 \%$ of patients showed moderate improvement in their blood glucose levels as a result of the diet and lifestyle modifications (Roy Chowdhury 2017).

\section{b) Use of fruit products, herb made skin-hair care products, etc. without any synthetic chemical}

A novel collection, packaging and transportation system are proposed for fruit pulp, fruit juices, other related products like fruit ice creams; skincare, hair care products, etc. of completely herbal origin. Following the described procedures, medicinal parts of the plants are to be collected, encapsulated, or packed without the use of any synthetic chemicals (like synthetic preservatives, stabilizers, etc.) and can be transported throughout the globe under a framed cold chain system (Pattanayak 2019b).

\section{ii) Succulent biomedicines}

The term succulent biomedicine is given to the paste, juice, or seed-powder of relevant parts of different medicinal plants collected as well as used in the succulent state. In this novel system of medicine, uses of synthetic chemicals are avoided at all the steps of preparation, encapsulation, packaging, storage and transportation of 
the medicines. This system is framed with some defined steps. After validation of their activities in succulent forms, the medicinal plant parts are to be collected in their succulent conditions from the area of their cultivation. Then after standardization of dose and performing toxicity studies, these can be mixed with biopreservatives and then may be capsulated by bioencapsulating materials, if required. Finally these are to be transported to patients throughout the globe and can be stored by the retailers under some specially designed cold chain facilities (Pattanayak 2020, Pattanayak 2021). As the succulent parts of the medicinal plants contain almost all the phytoconstituents present in the living plants, it is natural that they can show the highest level of activities in that form. In all other systems of medicine where the dry parts of the plants or their extracts are used have the limitation of presentation of only one or a few phytochemicals of the medicinal plant parts (Pattanayak et al. 2016b).

\section{CONCLUSION}

Plants and animals are two important entities of nature. Most animal species take plants as part of their diet. Many of the ape species take parts of plants for health benefits. The ancient people perhaps had a similar type of habit. But possibly due to problems in the storage of succulent plant parts and only seasonal or regional availability of fresh plants forced our predecessor to depend on the dried parts of the medicinal plants. Afterward, many systems were developed depending on the use of only the dry parts of the medicinal plants as medicines.

As the problem of preservation is not relevant at the present time and since many important phytochemicals are either reduced or lost in the dried or processed fruits, roots, or vegetable items, adoptive researches should be initiated for effective dietary use of succulent foods and succulent biomedicines. This can only lead to the development of different branches of the system, standardization of all related parameters, the establishment of herb-based medicine industries, and widespread application of the system for the benefit of mankind.

\section{REFERENCES}

Aggarwal BB, Sundaram C, Malani N, Ichikawa H (2007) Curcumin: The Indian solid gold (https://archive.org/details/ moleculartargets00bhar). Adv Exp Med Biol 595: 1-75.

Ambasta SP (1986). The useful plants of India. National Institute of Science Communication and Information Resources. CSIR, New Delhi.
Asthana A, Kumar A, Gangwar S, Dora J (2012) Pharmacological perspectives of Cynodon dactylon. Res J Pharmaceut Biol Chem Sci 3(2): 1135-1147.

Bharatan V (2008) Homeopathy and systematics: a systematic analysis of the therapeutic effects of the plant species used in homeopathy. Homeopathy 97(3): 122-128. DOI: 10.1016/j.homp.2008.04.002.

Capasso L (1998) 5300 years ago, the Ice Man used natural laxatives and antibiotics. Lancet 352(9143): 1864. DOI:10.1016/S0140-6736(05)79939-6.

CCRH - Central Council for Research in Homoeopathy (2018) Ministry of AYUSH, Govt. of India. https:// www.ccrhindia.nic.in/index 1 aspx $? 1 \mathrm{sid}=61 \& l e v=2 \& l i d=59 \&$ Regid $=0$ \&langid $=1$.

Chauhan A, Semwal DK, Mishra SP, Semwal RB (2015) Ayurvedic research and methodology: Present status and future strategies. Ayu 36(4): 364-369. DOI:10.4103/09748520.190699.

Chopra RN, Nayar SL, Chopra IC, Asolkar LV, Kakkar KK (1956) Glossary of Indian medicinal plants. Council of Scientific and Industrial Research, New Delhi, India.

Christenhusz MJM, Byng JW (2016) The number of known plants species in the world and its annual increase. Phytotaxa 261(3): 201-217. DOI:10.1007/978-0-387-46401-5_1.

Dwivedi G, Dwivedi S (2007) History of Medicine: Sushrutathe clinician-teacher par excellence. Indian J Chest Dis Allied Sci 49: 243-244.

Farnsworth, Norman R, Akerele, Olayiwola, Bingel et al. (1985) Medicinal plants in therapy. Bulletin of the World Health Organization, 63(ý6)ý: 965-981. https://apps.who.int/ iris/handle/10665/265180. [Accessed on 17.08.2021].

Khameneh B, Iranshahy M, Soheili V, Bazzaz BSF (2019) Review on plant antimicrobials: a mechanistic viewpoint. Antimicrobial Resistance Infection Control 8: 118. https:// doi.org/10.1186/s13756-019-0559-6.

Kutalek R, Prinz R (2005) African medicinal plants. In: Yaniv Z, Bachrach U. Handbook of medicinal plants, The Haworth Medical Press, New York, USA.

Meena AK, Bansal P, Kumar S (2009) Plants-herbal wealth as a potential source of ayurvedic drugs. Asian J Traditional Medic 4(4): 152-170.

Nirumand MC, Hajialyani M, Rahimi R, Farzaei MH, Zingue S et al. (2018) Dietary plants for the prevention and management of kidney stones: preclinical and clinical evidence and molecular 
mechanisms. Int J Mol Sci 19: 765. DOI:10.3390/ ijms 19030765 .

Pattanayak S, Dutta MK, Debnath PK, Bandyopadhyay SK, Saha B, Maity D (2012) A study on ethno-medicinal use of some commonly available plants for wound healing and related activities in three southern districts of West Bengal, India. Explor Anim Med Res 2(2): 97-110.

Pattanayak S, Mandal TK, Bandyopadhyay SK (2015a) Plants used to cure problems of flatulence and constipation in three southern districts of West Bengal, India. Explor Anim Med Res 5(2): 142-151.

Pattanayak S, Mandal TK, Bandyopadhyay SK (2015b) A study on use of plants to cure enteritis and dysentery in three southern districts of West Bengal, India. J Medic Plants Studies 3(5): 277-283.

Pattanayak S, Mandal TK, Bandyopadhyay SK (2016a) Ethno-gynaecological study of the medicinal plants traditionally used in southern districts of West Bengal, India. Indian J Traditional Knowledge 15(3): 482-486.

Pattanayak S, Mandal TK, Bandyopadhyay SK (2016b) Validation and therapeutic use of succulent plant parts - opening of a new horizon of alternative medicine. Explor Anim Med Res 6(1): 8-14.

Pattanayak S, Mandal TK, Bandyopadhyay SK (2016c) Ethnomedicinal study of plants used for protection and stimulation of liver in southern West Bengal, India. Explor Anim Med Res 6(2): 164-178.

Pattanayak S (2017) Processed foods - are they safe? Explor Anim Med Res 7(2): 125-131.

Pattanayak S (2018) Alternative to antibiotics from herbal origin - outline of a comprehensive research project. Current Pharmacogenomic Personalised Medic 16(1): 9 -62. DOI: $10.2174 / 1875692116666180419154033$.

Pattanayak S (2019a) Healthcare system using succulent parts of plants, Volume I: For infectious diseases. ISBN: 97893-5346-842-2.
Pattanayak S (2019b) Healthcare system using succulent parts of plants, Volume 2: Steps for production and marketing of some selected healthcare products. ISBN: 978-93-5391625-1.

Pattanayak S (2020) Succulent biomedicines - an effective way of getting protection against diseases through immunomodulation. Explor Anim Med Res 10(2): 112-123.

Pattanayak S (2021) Anti-COVID-19 biomedicines - a layout proposal for production, storage and transportation. The Open COVID J 1: 166-188. DOI: 10.2174/2666958702101010166.

Pearson H (2003) 250 years of Linnaeus' plant names celebrated. Nature 2003, https://doi.org/10.1038/news0308257.

Petrovska BB (2012) Historical review of medicinal plants' usage. Pharmacognosy Rev 6(11): 1-5. DOI:10.4103/09737847.95849 .

Rabe, Staden JV (1997) Antibacterial activity of South African plants used for medicinal purposes. J Ethnopharmacol 56: 81; Cited in: Meena AK, Bansal P, Kumar S (2009) Plantsherbal wealth as a potential source of ayurvedic drugs. Asian J Traditional Medic 4(4): 152-170.

Roy Chowdhury B (2017) Diabetes reversal by plant-based diet. J Metabolic Synd 6(4): 1000232. DOI: 10.4172/21670943.1000232 .

Roy Chowdhury B (2021) DIP diet plan, https:/dipdiet.in/ wp-content/uploads/2021/06/Dip-Diet-Plan-1.pdf

Sen U, Sen D (2005) Ayurveda Sar Samgraha (Bengali edn.). Swami Santadas Institute of Culture, Kolkata, India.

Solecki RS (1975) Shanidar IV, a Neanderthal flower burial in Northern Iraq. Science 190 (4217): 880-881. [Bibcode: 1975Sci. 190.880S doi:10.1126/science.190.4217.880; S2CID 71625677], downloaded 01.08.2021.

The wealth of India: A dictionary of Indian raw materials and industrial products (Industrial products-part I) (1949). Ind Med Gaz 84(10): 476-477.

Uphof JCT (1968) Useful species: Dictionary of economic plants. $2^{\text {nd. }}$ edn. Cramer, Wiirzburg, Stechert-Hafner, New York.

*Cite this article as: Pattanayak S (2021) Plants in healthcare: past, present and future. Explor Anim Med Res 11(2): 140-144. DOI: 10.52635/eamr11.2.140-144. 